\title{
O Curso de Etnodesenvolvimento e a formação diferenciada e intercultural: contribuições no contexto educacional, sociopolítico e cultural da Amazônia
}

\section{The Ethnodevelopment Course and differentiated and intercultural training: contributions in the educational,socio-political and cultural context of the Amazon}

\author{
Francilene de Aguiar Parente* \\ Irlanda do Socorro de Oliveira Miléo*
}

\begin{abstract}
RESUMO
$\mathrm{O}$ artigo analisa como o curso de Etnodesenvolvimento ofertado pela Universidade Federal do Pará/Campus Universitário de Altamira tem contribuído na formação acadêmica, política e profissional de estudantes advindos de povos indígenas e comunidades tradicionais no contexto da Amazônia. Situa por meio de uma abordagem descritiva-analítica das experiências vivenciadas desde o processo de criação e organização do curso, a partir das políticas públicas de ações afirmativas no território brasileiro, bem como sua metodologia e os desafios enfrentados para sua efetivação, em decorrência das questões institucionais. As reflexões elaboradas evidenciam que o curso de Etnodesenvolvimento tem contribuído para ampliar as possibilidades de atuação e negociação política desses agentes sociais a partir de seus lugares de pertença coletiva, assim como para uma formação diferenciada que possibilita e instrumentaliza sua inserção profissional no campo educacional nos diferentes territórios da região amazônica.
\end{abstract}

Palavras-chave: Etnodesenvolvimento. Educação superior diferenciada. Formação Diferenciada. Pertença.

* Universidade Federal do Pará. Faculdade de Etnodiversidade. Altamira, Pará, Brasil. E-mail: faparente@gmail.com - https://orcid.org/0000-0003-2740-9343 E-mail: irlanda@ufpa.br - https://orcid.org/0000-0002-7075-6503 


\begin{abstract}
This article analyzes how the Ethnodevelopment course offered by the Universidade Federal do Pará [Federal University of Pará]/Altamira University Campus has contributed to the academic, political and professional training of students belonging to indigenous peoples and traditional communities in the context of the Amazon. It provides a descriptive-analytical approach to their experiences, starting with the process of the creation and organization of the course, based on affirmative public policies undertaken in Brazil, as well the course methodology and the challenges faced for the course to be implemented in the light of institutional issues. The reflections put forward show that the Ethnodevelopment course has contributed to expanding possibilities of action and political negotiation by these social agents based on their spaces of collective belonging, as well contributing to differentiated training that enables and instrumentalizes their inclusion as professionals in the field of education in the different territories of the Amazon region.
\end{abstract}

Keywords: Ethnodevelopment. Differentiated Higher Education. Differentiated Training. Belonging.

\title{
Primeiras aproximações - Etnodesenvolvimento: da construção da noção à oferta do curso
}

O curso de graduação em Etnodesenvolvimento da Universidade Federal do Pará (UFPA) - Campus Universitário de Altamira, é uma experiência-piloto no Brasil e tem suas diretrizes fundamentadas nas discussões estabelecidas a partir da parceria entre universidades públicas, agências de fomento e movimentos sociais. Mas, antes de passarmos à apresentação do curso em si, é necessário situarmos o significado da noção de etnodesenvolvimento que subsidia os pressupostos epistemológicos, filosóficos e teórico-práticos desse curso.

A noção de etnodesenvolvimento foi definida entre os anos 1970 e 1980 do século XX, em resposta ao desenvolvimento proposto, e tem como seus principais idealizadores Rodolfo Stavenhagen e Guillermo Bonfil Batalla. Entretanto, sua discussão, de acordo com Antonio Carlos de Souza Lima, Maria Barroso-Hoffmann e Sidnei Clemente Peres (2002), e Ricardo Verdum (2006), remete ao pós-segunda guerra mundial, momento em que o processo de descolonização das nações na África, na Ásia e no Caribe estava em voga e surgia a preocupação com o desenvolvimento sob o prisma econômico. 
Para Stavenhagen (1984, p. 18), um dos principais expoentes na discussão sobre etnodesenvolvimento,

[...] significa que uma etnia autóctone, tribal ou outra, detém o controle sobre suas próprias terras, seus recursos, sua organização social e sua cultura, e é livre para negociar com o Estado o estabelecimento de relações segundo seus interesses $[\ldots]$.

Nessa direção, Verdum (2006) considera que a noção de etnodesenvolvimento como proposta por Stavenhagen implica, conforme propõe Bonfil Batalla (2006, p. 73, tradução nossa), que

[...] as comunidades sejam efetivamente gestoras do seu próprio desenvolvimento, que a elas seja garantido o direito de formar seus quadros técnicos (engenheiros, professores, médicos etc.) e estruturar e gerir as unidades político-administrativas responsáveis pela gestão dos seus territórios.

O etnodesenvolvimento se constitui, assim, como ferramenta de luta política e conquista de direitos diferenciados para a garantia da autonomia cultural desses sujeitos sociais, com vistas à concretização do projeto de futuro que almejam para suas sociedades, segundo Little (2002, p. 40), o "guia principal para o estabelecimento das condições necessárias para a implementação do etnodesenvolvimento". Autonomia, principalmente no caso dos povos indígenas, é, na maioria dos casos, vista pelo Estado enquanto uma ameaça à soberania nacional, conforme destaca Bartolomé (2006, p. 41), “[...] que o cerne da questão da autonomia está na manutenção (ou reconquista, se for o caso) de um alto grau de controle sobre a tomada das decisões que afetam o grupo étnico local".

Nesse sentido, um e outro se complementam: a implementação de políticas na perspectiva etnodesenvolvimentista amplia as possibilidades de autonomia dos coletivos étnicos, ao mesmo tempo que a autonomia também permite a consolidação do etnodesenvolvimento de povos e comunidades tornados vulneráveis. Embora a noção de etnodesenvolvimento no Brasil esteja associada aos povos indígenas, toda a discussão no cenário internacional evidencia que pode ser aplicada aos povos tradicionais de uma maneira geral. Desse modo, a proposta de políticas educacionais pautadas nessa perceptiva contrapõe-se aos modelos 
educativos universalistas e monoculturais observados nos dias atuais no cenário brasileiro, que trazem em si desenhos seletivos e focalizados que contribuem para consolidar a desigualdade e exclusão social (BONETI, 2006; CANDAU, 2011).

Nos anos 1990, a discussão a respeito do etnodesenvolvimento foi tomada por quadros do Banco Mundial, marcando outra característica do processo de construção de etnodesenvolvimento de um povo indígena, que é a parceria com agências de fomento, nacionais e/ou internacionais, conforme destacam Souza Lima, Barroso-Hoffman e Peres (2002). Essa movimentação no plano internacional acerca desse debate repercutiu no cenário indigenista brasileiro, em decorrência do estabelecimento de parcerias entre as organizações, associações indígenas e as universidades públicas, e passou a influenciar um novo modelo de formação acadêmica, sobretudo, por meio da criação de pós-graduações instituídas a partir de recursos da Fundação Ford e de agências brasileiras, como a Coordenação de Aperfeiçoamento do Pessoal do Ensino Superior (CAPES), o Conselho Nacional de Desenvolvimento Científico e Tecnológico (CNPq) e a Financiadora de Estudos e Projetos (FINEP). Além dessas agências de fomento nacionais e/ou internacionais e dos profissionais formados para trabalhar com etnodesenvolvimento, os povos indígenas também contavam com a atuação desses profissionais a partir de Organizações Não Governamentais (ONGs) voltadas para o campo indigenista.

Foi a partir disso que nasceu a iniciativa de ofertar pela Universidade Federal do Pará (UFPA) um curso de Etnodesenvolvimento. É sobre o processo de articulação e implantação do curso e os alcances políticos de sua formação como proposta de inclusão de povos e comunidades tradicionais na UFPA e a afirmação de seus coletivos de pertença que trata o artigo em tela. Experiência vivida muito proximamente por nós, autoras, por termos integrado o grupo de professores que atuou diretamente na proposição do curso, bem como em sua implantação e desenvolvimento até os dias atuais, no ensino, pesquisa e/ ou extensão, compondo as equipes que fizeram as seleções e, posteriormente, atuando ativamente no curso.

Ao adotarmos a abordagem descritiva-analítica das experiências vivenciadas como docentes do curso, desde o processo de criação, organização e operacionalização do mesmo a partir das políticas de ações afirmativas, buscamos situar, para além de percepções lineares, os processos socioculturais e institucionais que incidiram nas tomadas de decisões, no sentido de elucidar as práticas que foram se materializando, tanto na dimensão da proposta pedagógica como no processo de concretude das relações construídas entre os diferentes sujeitos coletivos (instituição, professores, estudantes, movimentos e grupos sociais) que, direta e indiretamente, tornaram-se referência para o curso. Ou seja, buscamos evidenciar um quadro descritivo-analítico tal como a 
descrição densa preconizada por Geertz (1989), considerando os atores sociais como produtores e produtos da cultura tecida por meio das relações sociais, interpretativa por excelência.

O curso de Bacharelado e Licenciatura em Etnodesenvolvimento apresenta algumas especificidades e desafios: é o único no nível de graduação até o momento no Brasil com essas características; reúne diferentes pertenças sociais em uma única turma; apresenta metodologia diferenciada; é resultado da atuação política de movimentos sociais e da discussão política interna à UFPA; e surgiu em meio a uma série de discussões acerca de políticas afirmativas na UFPA, em meados de 2007 e início de 2008, fomentado pelo debate em nível nacional a respeito das ações afirmativas, resultante da Conferência de Durban em 2001, o que promoveu significativos avanços no debate público sobre o tema (PIOVESAN, 2006). Aspecto que mobilizou os docentes dos campi de Altamira, Belém e Marabá que vinham desenvolvendo suas atividades de ensino, pesquisa e extensão com povos e comunidades diferenciadas, como agricultores, povos indígenas e quilombolas.

A criação dessa graduação compôs o plano de expansão da UFPA através do Programa de Apoio a Planos de Reestruturação e Expansão das Universidades Federais (REUNI), e sua construção deu-se a partir das discussões no âmbito do Programa de Políticas Afirmativas para Povos Indígenas e Populações Tradicionais (PAPIT), criado em 2008. Importa destacar que o REUNI é um programa do governo federal criado pelo Decreto ${ }^{\circ}$ 6.096, de 24 de abril de 2007 (BRASIL, 2007), e tem por objetivo favorecer a ampliação ao acesso e a permanência na educação superior, criando condições para que as universidades federais promovam a expansão física, acadêmica e pedagógica da rede federal de educação superior.

O curso de Etnodesenvolvimento foi aprovado em 2009, conforme a Resolução do CONSEPE/UFPA Nº 3.860, de 22 de maio de 2009 (UNIVERSIDADE FEDERAL DO PARÁ, 2009), e inserido nas políticas afirmativas da UFPA como Turma Especial ${ }^{1}$. Como tantos outros cursos voltados para um público socialmente diferenciado e ofertados pelas universidades brasileiras, a parceria estabelecida com instituições que fomentam esses tipos de iniciativas foi um caminho percorrido. As ações necessárias à elaboração do Projeto Pedagógico de Curso (PPC) e implementação do curso de Etnodesenvolvimento na UFPA tiveram o apoio financeiro da Ford Foundation (FFORD), instituição que financiou por dois anos (2008-2010) o PAPIT. A partir do PAPIT apoiou-se a formação de um Grupo de Trabalho (GT) Pró-curso de

1 Trata-se da política afirmativa específica aos cursos destinados exclusivamente a povos indígenas e tradicionais, como Etnodesenvolvimento e Educação do Campo, na UFPA. 
Etnodesenvolvimento, composto por representantes docentes de faculdades do Campus de Altamira/UFPA, por ser o espaço institucional em que o curso seria ofertado, e pela equipe do PAPIT.

As ações desse GT também contaram com o apoio de intelectuais orgânicos atuantes nos movimentos sociais indígenas e demais povos tradicionais representantes do público-alvo do curso. Ao GT também coube discutir planos de concursos para docentes que atuariam no curso, sendo inicialmente abertas vagas para quatro cadeiras: Linguística, Antropologia, Arqueologia e Direitos Humanos. Os docentes aprovados nos concursos passaram a integrar o GT e se inseriram nas discussões acerca da sua implantação. Após várias reuniões do GT em Altamira e Belém, assim como de discussões via e-mail, o desenho curricular do curso foi elaborado com o objetivo de fomentar a preparação de: "recursos humanos oriundos de povos indígenas e populações tradicionais dotados de capacidade de gerenciar informações e contatos com possibilidade de intervir socialmente a partir de auto-reflexão sistemática" (UNIVERSIDADE FEDERAL DO PARÁ, 2010, p. 9).

$\mathrm{O}$ ingresso no curso acontece a cada dois anos. Ele se dá através do Processo Seletivo Especial (PSE), com edital diferenciado do edital universal, sendo ofertado em período intensivo. Para a oferta da primeira turma, houve uma ação do PAPIT nas bacias dos rios Xingu e Araguaia-Tocantins para fazer um inventário de povos e comunidades tradicionais que se encontram nessas regiões; após esse mapeamento, foram organizadas idas às comunidades-alvo do curso para apresentá-lo e solicitar indicação de candidatos pelas lideranças comunitárias.

Em 2010/2011 ocorreu o primeiro PSE para o curso de Etnodesenvolvimento, com candidaturas apresentadas a partir dos campi de Altamira e Belém. Foram ofertadas 45 vagas, as quais foram preenchidas. As demais ofertas de turmas ocorreram nos anos de 2013, 2014 e 2015 em Altamira, e no ano de 2016 houve a oferta de uma turma flexibilizada para o Campus Universitário de Soure/UFPA, localizado no Marajó, como licenciatura e bacharelado. Em 2019, a partir de sua reorganização curricular orientada pela Resolução do Conselho Nacional de Educação N ${ }^{\circ}$. 02/2015 (BRASIL, 2015), o curso passa a ser oferecido como licenciatura e uma nova turma é ofertada em Altamira (UNIVERSIDADE FEDERAL DO PARÁ, 2019). As turmas, em geral, são formadas por quilombolas, indígenas, agricultores familiares, pessoas do movimento negro, ribeirinhos, extrativistas e pescadores, variando o número de sujeitos de cada pertença. Essas diferentes pertenças são reunidas em uma sala de aula, em $8 \mathrm{~h}$ de aula por dia, durante dois meses a cada tempo-universidade (TU) - (janeiro/ fevereiro e julho/agosto). 


\section{Diferentes, mas iguais? Construindo possibilidades de interação entre as pertenças e descontruindo o preconceito na UFPA}

O Curso de Etnodesenvolvimento configura-se como uma rede dialógica entre saberes e sujeitos de diferentes pertenças, e foi proposto no sentido de superar o modelo cartesiano de boa parte das políticas educacionais que, segundo com Boneti (2006), evocam um conjunto de diretrizes, objetivos e metas planejadas e regulamentadas por uma correlação de forças complexas que englobam interesses locais, nacionais e internacionais, a partir de um padrão homogeneizador dos imaginários coletivos, observando-se assim a ausência de diferentes vozes identitárias na elaboração das políticas públicas educacionais.

Numa proposição contra-hegemônica, seu projeto pedagógico orientado por um currículo referenciado pela interculturalidade nos possibilitou repensar e ressignificar diferentes aspectos e componentes da cultura escolar e de todo sistema de ensino, a partir de um permanente movimento dialético de comunicação e aprendizagens entre cultura, identidades, conhecimentos, saberes e práticas, retroalimentado pelo diálogo simétrico e interativo entre os diferentes grupos socioculturais, colocando-se, portanto, como "uma tarefa social e política que interpela o conjunto da sociedade, que parte de práticas e ações sociais concretas e conscientes e tenta criar modos de responsabilidade e solidariedade; e uma meta a alcançar" (WALSH, 2001 apud CANDAU, 2008, p. 11); sem perder de vista a necessidade de considerar, na materialidade desse currículo, o intercâmbio entre saberes tradicionais e saberes oficiais.

Por políticas de ação afirmativa compreendemos um conjunto de medidas especiais e temporárias que buscam combater as desigualdades históricas advindas das discriminações a determinados povos, comunidades, grupos no interior de uma sociedade, sem agir sobre o direito a igualdade. De acordo com Flávia Piovesan (2006, p. 40-41), as ações afirmativas permitem remediar processos discriminatórios, ao mesmo tempo que

[...] cumprem uma finalidade pública decisiva ao projeto democrático, que é a de assegurar a diversidade e a pluralidade social. Constituem medidas concretas que viabilizam o direito à igualdade, com a crença de que a igualdade deve se moldar no respeito à diferença e à diversidade.

Trata-se, acima de tudo, da tentativa de alcance do ideal de justiça redistributiva com reconhecimento de identidades; em outras palavras, uma 
igualdade que reconheça as diferenças e uma diferença que não (re)produza as desigualdades, conforme orienta e acredita Boaventura de Souza Santos para a realização da igualdade (SANTOS, 2003), e que restitua "uma igualdade que foi rompida ou que nunca existiu", como informa Sabrina Moehlecke (2002, p. 201), que pode se constituir de diferentes formas, a depender dos desigualdades locais. No caso da UFPA, uma das vias encontradas foi a garantia da educação a povos indígenas e comunidades tradicionais por meio das políticas de ação afirmativa.

$\mathrm{O}$ fato de pessoas social e etnicamente diferentes entre si formarem uma única turma de graduação na UFPA representa um desafio em vários campos: administrativamente; para o trabalho docente; para os demais estudantes da universidade e, principalmente, para os discentes do curso, que se viram colocados em uma arena comum de formação, negociação de interesses e construção de diálogos. Isso porque os perfis dos estudantes são bem variados.

Nem todos são lideranças políticas em seus grupos de pertença, e alguns, principalmente os indígenas, que em sua maioria moram na cidade de Altamira, falam com timidez da identidade étnica a que pertencem. Em relação aos agricultores, são oriundos de formações políticas promovidas nas Comunidades Eclesiais de Base (CEBs, da Igreja Católica) e da militância nos movimentos do campo ou de mulheres se expressam a partir do seu lugar de luta; outros discentes também contam com a experiência de educação diferenciada das Casas Familiares Rurais (CFRs) e do Programa Nacional de Educação na Reforma Agrária (PRONERA) do Instituto Nacional de Colonização e Reforma Agrária (INCRA), o que de certa forma indica o relativo sucesso de tais formações, ao menos no que tange à continuidade da escolarização de pessoas do campo, que chegam à universidade por diferentes formas de ingresso.

Os quilombolas, por outro lado, formam um grupo misto de pessoas com reconhecida liderança política e outras com grande potencial para formação, especialmente com relação às questões de gênero no interior do grupo étnico. Ribeirinhos e pescadores falam com propriedade sobre suas identidades e atuações políticas; e as representações do movimento negro demandam do curso discussões referentes aos problemas que enfrentam em suas vivências na área urbana de Altamira e (con)vivendo com outros tantos movimentos e identidades.

O perfil diversificado dos estudantes, os diferentes sujeitos coletivos e suas pertenças constituem um mosaico intercultural marcado por interações, conflitos, dissensos, que se materializam no chão da universidade, constituindose como desafios a nós, docentes e discentes; mas, ao mesmo tempo, nos dão uma perspectiva de infinitas aprendizagens proporcionadas nesses embates dialógicos de empoderamentos, ressignificações, (re)construções e afirmações identitárias. Essa manipulação das pertenças e identidades étnicas deve ser entendida como 
uma estratégia de resistência a diferentes situações sociais vividas ao longo das trajetórias individuais e coletivas, assim como a políticas universalistas do Estado em relação aos sujeitos em questão e seus coletivos (SANTOS, 2003).

Essa dinâmica pautada na interculturalidade promove uma educação dialógica com base no reconhecimento do "outro", afirmando relações horizontais entre os diferentes sujeitos coletivos envolvidos no ato educativo, à medida que, como destaca Candau (2008), a educação na perspectiva intercultural, como negociação cultural, ao possibilitar enfrentamento nos conflitos ocasionados pela assimetria de poder entre os diferentes coletivos, pode ser capaz de

[...] favorecer a construção de um projeto comum, pelo qual as diferenças sejam dialeticamente integradas. A perspectiva intercultural está orientada à construção de uma sociedade democrática, plural, humana, que articule políticas de igualdade com políticas de identidade (CANDAU, 2008, p. 52).

No primeiro dia de aula, no momento de suas apresentações ao coletivo, é perceptível a surpresa nos rostos dos estudantes, particularmente em relação aos indígenas e quilombolas. Há ainda uma expectativa de encontrar os indígenas e quilombolas dos livros didáticos e redes de televisão; homogeneamente "pintados" e reificados como imagem de pureza étnica. Mais interessante ainda é que essa representação é associada à imagem do outro, não a si mesmo. A referência a si, na maioria das vezes, é de que "sou indígena, quilombola ou agricultor", mas ao outro expressa questionamento de sua identidade, o que pode gerar uma série de conflitos; assim como o posicionamento político em relação a determinados temas ou situações reais que os aflige como coletivo. Um dos desafios é fazê-los compreender que essa é/era a representação que o "branco"/ ocidental ideologicamente faz(ia) deles como estratégia para negação de suas identidades e direitos; assimilar e reproduzir esse discurso é assumir sua posição de superioridade, relegando aos etnicamente diferenciados posição inferior nas relações sociais. Perceber que a negação de um dos coletivos diferenciados recaía sobre as identidades de outros grupos, posto que apesar de diferentes eles são/eram vistos, aos olhos dos que propõem a homogeneização em nome do crescimento da nação, como empecilhos ao progresso.

Se na sala de aula o grupo se fortalece, fora dela a situação é mais complexa, pois os estudantes de diferentes pertenças sociais são colocados em uma arena comum de formação (e de formadores), negociação de interesses, especialmente em relação ao movimento estudantil que não consegue incorporar as demandas de estudantes diferenciados, a exemplo das vagas para permanência na casa de estudante, extensão dos prazos para inscrição em bolsas de estudo (que exigem 
documentação que os estudantes muitas vezes não têm, como comprovante de renda e residência).

Documentação que também são necessárias para o PSE, e que devido a falta de articulação e problemas de comunicação entre o movimento estudantil e os estudantes diferenciados, acabam por inviabilizar tanto a inscrição ao processo seletivo como a habilitação dos aprovados, o que exige dos discentes e docentes a construção de diálogos em espaços diversos para a permanência dos discentes e a manutenção do curso na instituição.

É comum os discentes comentarem que "na sala do Etno era de um jeito, fora da sala as pessoas não os reconheciam"; na sala, são reconhecidos como coletivos diferenciados e tinham sua identidade étnica positivada, fora da sala as desconfianças e disputas são ativadas, seja pela entrada na universidade pelas políticas afirmativas, via PSE, lidas como facilitadoras para esses grupos, que por isso não são merecedores de estar na universidade em igualdade de condições, porque não tiveram o mérito de "passar" no vestibular universal, seja porque não eram/são reconhecidos em suas identidades étnicas fora dos espaços geográfica e socialmente estabelecidos para o enquadramento identitário.

Em vista disso, o trabalho docente mostra-se sempre desafiador com uma turma diversa que tem na oralidade o ponto alto dos debates. Por outro lado, a escrita é algo a ser trabalhado entre essas pessoas. A opção pela qualidade da leitura, discussão e escrita, em detrimento da quantidade de material presumivelmente trabalhado, tem se mostrado o equilíbrio para a turma, o que varia conforme a composição de cada uma. Essas práticas são adotadas como estratégias de envolver o coletivo numa dinâmica em que as relações intersubjetivas e culturais entre professores e estudantes sejam tecidas muito mais por uma reflexão epistemológica que efetivamente impactam a vida para além da escola e das salas de aulas, transpondo desse modo, os conhecimentos abstratos e cartesianos (SANTOS, 2008). Essa proposição da práxis educativa fundamentada na dimensão político-epistemológica, não estabelece uma ordem curricular pré-fixada; ao contrário, possibilita a produção do currículo no fluxo dos acontecimentos e experiências da vida concreta daquelas pessoas.

\section{A inserção no curso de Etnodesenvolvimento pelo processo seletivo especial}

À medida que as atividades acadêmicas do curso avançam, o cenário de timidez do início dá cada vez mais lugar à afirmação e à argumentação das 
identidades socialmente diferenciadas. Atividades curriculares que problematizam a questão da identidade ajudam os discentes a refletirem sobre a construção de suas identidades individuais e coletivas, fortalecendo os grupos dentro da sala, mas de forma a dialogar e não tanto disputar entre si. Ao mesmo tempo em que as diferentes identidades coletivas ganham maior nitidez, a dinâmica do processo de construção delas mostra que essa nitidez não corresponde a fronteiras fixas e rígidas, mas fluídas, como afirma Hall (2000). E no curso essa fluidez se dá também no sentido de se poder "transitar" entre duas pertenças, como foi o caso de uma discente que ingressou no curso como agricultora, filha de mãe indígena e de pai agricultor, que atualmente se autodeclara indígena.

Uma das batalhas travadas internamente do ponto de vista institucional na UFPA foi e ainda é, o combate à ideia de que os candidatos etnicamente diferenciados podem ser contemplados pelos editais de seleção universais. Houve um investimento do GT Pró-curso de Etnodesenvolvimento em discutir com os setores da UFPA responsáveis pela construção dos editais de seleção sobre o que se tratava o atendimento aos candidatos socialmente diferenciados, inclusive com assessoria jurídica de docentes ligados ao GT. Alguns dos docentes do respectivo GT participaram de reuniões com membros da Comissão Permanente de Processos Seletivos da UFPA (COPERPS/UFPA) com o fim de discutir a minuta de edital de seleção proposta pelo GT e, desta forma, construir o documento final. Nessas reuniões, muitas eram as preocupações por parte dos membros da COPERPS, entre elas situa-se a legalidade do processo de seleção diferenciada, e mesmo algumas das opiniões emitidas marcaram o processo de construção do edital do PSE, segundo destaca Parente (2014), evidenciando que as instituições de ensino superior ainda precisam avançar de forma significativa na concretude das políticas públicas de ações afirmativas e atendimento à diferença (OLIVEIRA; PARENTE; DOMINGUES, 2017).

Importa destacar que por se tratar de um curso alinhado às políticas públicas de ações afirmativas desenvolvidas no território brasileiro, sua dinâmica e organização diferenciada e intercultural (PIOVESAN, 2006; CANDAU, 2011) provocou a partir do ano de 2013 mudanças na forma de promover o PSE para as políticas afirmativas com reservas de vagas para povos indígenas e quilombolas e turmas especiais. Mudanças que contemplam as demandas tanto do curso de Etnodesenvolvimento como do Curso de Licenciatura em Educação do Campo, que integram a Faculdade de Etnodiversidade da UFPA/Campus de Altamira. Todos os candidatos passaram por uma primeira etapa do processo constituído por prova objetiva e de redação e, posteriormente, realizaram a entrevista. Até o último processo seletivo, realizado no ano de 2019, a prova objetiva só foi aplicada aos cursos de educação do campo, que têm público específico e dinamicidade diferenciada de outros cursos do programa de políticas afirmativas. 
Outra discussão desenvolvida com a COPERPS diz respeito ao conteúdo a ser cobrado no PSE para o curso de Etnodesenvolvimento, pois a oralidade entre os povos indígenas e tradicionais precisaria ser contemplada e valorizada no processo. Havia, por parte de alguns membros da COPERPS, a defesa de se aplicar aos candidatos uma prova de conhecimentos gerais, como ocorre no vestibular universal, mas isso foi debatido por membros do GT como não sendo uma forma adequada de atender às especificidades dos candidatos ao curso. Após muito diálogo, foi aprovada a constituição de uma Comissão nomeada pela COPERPS com o objetivo de realizar o PSE para o curso de Etnodesenvolvimento. As etapas do PSE para esse curso constituem-se de uma redação sobre temas voltados à realidade do público-alvo e uma entrevista com roteiro elaborado também pela comissão. Selecionada a primeira turma para o curso, começaram os desafios para o funcionamento cotidiano dele ${ }^{2}$.

Em relação às nossas dificuldades em materializar a proposta do curso, que no início, iam desde as salas que comportassem 45 discentes a professores com perfil acadêmico de atuação política, esbarrando a cada semestre com os questionamentos de que "havia profissional no campus [de Altamira] que pode ministrar a disciplina?", nos dias atuais se voltam ainda aos problemas concernentes à demanda de docentes para atuar no curso e à inserção e reconhecimento profissional do egresso do curso, devido ser uma área de atuação profissional recente. O diálogo com a coordenação do Campus e com a Reitoria da UFPA tem sido sempre no sentido de enfatizar os compromissos assumidos pela própria UFPA quando da aprovação do curso, e que integram o seu Plano de Desenvolvimento Institucional (PDI) 2001-2010 e no quadriênio 2011$2015^{3}$, que definia como princípio institucional a reestruturação do modelo de ensino, onde delineia que o panorama de pobreza e vulnerabilidade dos grupos sociais regionais deve ser assumido enquanto dívida social; o respeito à ética e à diversidade étnica, cultural e biológica; o pluralismo de ideias e de pensamento; o ensino público e gratuito; a defesa dos direitos humanos e a preservação do meio ambiente (UNIVERSIDADE FEDERAL DO PARÁ, 2002, 2011).

Embora o respeito à diversidade étnica, cultural e biológica tenha sido presente para a inclusão dos que são tratados como diferentes desde o início do processo, na medida em que utilizávamos desse argumento para a garantia de

2 Esses são exemplos trazidos para que se consiga observar e dimensionar a importância dos impactos transformativos de cursos diferenciados e/ou políticas específicas para povos indígenas e comunidades tradicionais na instituição, na medida em que, dentre outras coisas, questionam as políticas universalizantes e contribuem no processo de construção de uma universidade mais justa, participativa e inclusiva.

3 Período em que o curso estava sendo efetivo na instituição. 
direitos diferenciados éramos, e ainda somos, lembrados de que a "universidade é de todos" e trata todos diferenciadamente, o que entendíamos muito mais como a universalização e homogeneização da diferença para evitar privilégios (PARENTE, 2014). Isso porque, o respeito aos princípios da instituição acima expostos implica não somente na promoção de políticas afirmativas para a entrada e inclusão de povos indígenas, quilombolas, agricultores, negros e outros povos e comunidades diferenciadas na universidade, mas acima de tudo a garantia de sua permanência, por meio de bolsas de estudo e de apoio institucional para a moradia. Para dar uma noção das dificuldades decorrentes de uma política de ação afirmativa parcialmente implementada, toma-se o caso de Altamira, Pará (PA).

Desde 2010, as ações afirmativas para povos indígenas e comunidades tradicionais passaram a ser uma realidade concreta na instituição. Nesse mesmo período, é implantada a terceira maior hidrelétrica do mundo, Belo Monte, na região de Altamira, Estado do Pará. Não só o número da população quase triplicou ao longo dos anos, como a especulação imobiliária cresceu vertiginosamente no município e região. Por sua vez, a Casa do Estudante do Campus Universitário de Altamira não comporta o número de estudantes que dela precisam ${ }^{4}$. Diante disso, a situação tem sido bastante desgastante, porque a cada semestre que inicia problemas antigos são revividos sem que se consiga observar avanços em sua resolução.

É claro que o fato gera uma série de transtornos em decorrência dos discentes fazerem um grande esforço para terem onde ficar e não passar fome. Dependendo do semestre, e da situação encontrada, ficam na Casa do Estudante, dispersos por espaços vagos na instituição, o que tem melhorado ao longo dos anos, mas ainda carece de articulações, inclusive por parte da coordenação do curso e direção da faculdade, visando a garantia do direito à educação. Em alguns momentos, faz-se necessário alugar espaços externos à instituição, com o auxílio dos professores, para que os discentes possam ficar alojados durante o período presencial do curso. Inclusão não pode se resumir ao acesso ao ensino superior. Essas situações demarcam a necessidade de garantir a entrada e a permanência do estudante no ensino superior, com alojamento, bolsas e assessoria pedagógica, especialmente nos primeiros anos de execução da política, dada a importância de unificar o entendimento sobre o que ela significa e suas repercussões, caso contrário fica-se sujeito aos entendimentos subjetivos e cheios de preconceito da burocracia acadêmica.

4 Aliás, mesmo que comportasse, o texto regimental da Casa do Estudante Universitário do Campus de Altamira privilegia claramente os discentes do período extensivo da UFPA (leia-se março a junho e agosto a dezembro). 
Entretanto, é preciso que se diga, a política de assistência estudantil melhorou ao longo desse tempo por conta da atuação exercida pelos povos indígenas e comunidades tradicionais, especialmente os que acessaram a universidade por meio das políticas de ação afirmativa para turmas especiais, como os do curso de Etnodesenvolvimento, que pressionaram a instituição para a mudança de critérios para o acesso às bolsas, assim como o calendário de seleção e pagamento para os alunos dos cursos intensivos da UFPA(OLIVEIRA; PARENTE; DOMINGUES, 2017).

Por certo, a inclusão de povos indígenas e comunidades tradicionais na universidade tem proporcionado excelentes espaços de luta e diálogo para o acolhimento de fato da diversidade na burocracia universitária. Mas, independentemente das condições em que se realiza o curso, pode-se afirmar seu sucesso no que tange à formação de pessoas etnicamente diferenciadas, que hoje estão atuando em diferentes municípios da região do Xingu e Transamazônica, Ilha de Marajó, Tapajós, região Tocantina, Bragantina e Salgado Paraense; em quilombos, aldeias indígenas, projetos de assentamento e comunidades rurais, Casas Familiares Rurais (CFRs), áreas urbanas dos municípios; no ensino, na pesquisa, na extensão, em diferentes espaços, como técnicos das prefeituras de suas respectivas cidades e nos movimentos sociais e indígenas de onde provêm.

Além disso, entre os docentes que atuaram e atuam no curso, ouve-se falar que a metodologia empregada no Etnodesenvolvimento os instiga a repensar as ações didático-pedagógicas empregadas para as turmas que entraram na UFPA via edital universal, principalmente no que diz respeito a fazer do ensino algo mais próximo da realidade de vida dos discentes. Ações que têm promovido ação diferenciada em seus coletivos de pertença e possibilitado a circulação desses na universidade, que está começando a ser vista por eles como futuro a ser concretizado. Passo importante para isso foi a entrega do prédio do curso, ocorrida em julho de 2013. Um espaço próprio para o curso e o público diferenciado constitui-se estratégia política para os movimentos sociais e para a manutenção do curso na UFPA.

Reconhecemos que a demanda atual sobre o curso também é consequência do sucesso da formação das primeiras turmas (hoje estamos finalizando a quarta turma do total de cinco oferecidas até o presente momento), que vem se destacando na atuação política na região, participando de maneira qualificada das discussões sobre os problemas que afligem seus coletivos e a sociedade em geral, mesmo que essa atuação se dê de maneiras diferenciadas; assim como se tem obtido resultados significativos na luta pela inclusão de sua formação em postos nos governos municipais, seja como contratados na educação básica, o caso de muitos dos discentes que atuam no ensino, seja na inclusão de disciplinas no currículo escolar para que alunos formados em Etnodesenvolvimento tenham competência para ministrar, como o ocorrido entre os quilombolas da Ilha de 
Marajó e agricultores na Transamazônica, o que evidencia a potencialidade dos curso para a região amazônica .

\section{A Metodologia da Alternância: possibilidades e limites no curso}

A metodologia que orienta as ações didáticas e pedagógicas empregadas em sala de aula difere daquelas adotadas em turmas convencionais em alguns quesitos: quantidade de material utilizado para leitura e discussão; a discussão dos textos é feita a partir da relação desses textos com as experiências de vida e atuação política dos estudantes dentro e fora dos locais de pertença; as disciplinas são compartilhadas com professores de diferentes áreas do conhecimento e que dialogam entre si; as experiências dos estudantes são a matéria-prima para o desenvolvimento das atividades curriculares; durante as aulas são construídos os roteiros para o que os estudantes devem desenvolver no tempo-comunidade; os tempos-comunidades são acompanhados por professores do curso e os relatórios entregues servem de material para o seminário de abertura do próximo tempo-universidade, assim como nas disciplinas; as pesquisas realizadas nos tempos-comunidades são usadas como subsídios para a construção do trabalho de conclusão de curso (OLIVEIRA; PARENTE; DOMINGUES, 2017).

Como se vê, os docentes que atuam no curso de Etnodesenvolvimento enfrentam o desafio de acompanhar o processo formativo dos discentes ao longo do curso e não apenas em momentos pontuais. Isso limita o número de professores que pode se dedicar ao curso, o que vem sendo superado pelo trabalho em equipe dos docentes que atuam no Campus de Altamira e em outros campi da UFPA.

Destacamos ainda que as ações formativas que representam uma pedagogia diferenciada e intercultural, entendida como um processo teórico-prático em diálogo com os sujeitos coletivos e seus territórios de pertença (CANDAU, 2008; ARROYO, 2012), superam o modelo cartesiano de conhecimento e têm como fio condutor a Pedagogia da Alternância como fundamentação estruturante e do percurso curricular e pedagógico, que tem como princípio basilar uma prática sociopedagógica que articula tempos e espaços de aprendizagens, buscando mobilizar saberes experienciais e teóricos que exprimem adquirem significação nos territórios de pertenças a partir de vivências pedagógicas concretas (PARENTE; LOPES; MILÉO, 2020).

A metodologia da pedagogia da alternância foi adotada a partir dos anos 1960, baseada em experiências francesas de educação entre filhos de agricultores, que não se identificavam com o estudo regular pois o distanciava do trabalho nas 
propriedades rurais de seus pais; trabalho e estudo eram vistos pela educação regular da época como espaços e tempos não passíveis de integração. As primeiras experiências no contexto brasileiro ocorreram, primeiramente, nas Escolas Famílias Agrícolas (EFAs) e Casas Familiares Rurais (CFRs); organizada em atividades curriculares presenciais, no chamado tempo escola (TE) e em atividades realizadas no tempo comunidade (TC) a que pertencem os estudantes do curso, a pedagogia da alternância tem se mostrado ferramenta imprescindível na conjugação de diferentes experiências formativas, onde diferentes sujeitos (a partir da identidade que os aproximou, docentes e discentes), ocupam papéis sociais diversos, dialogam sobre as diversas experiências que os constituem e conformam quem são (PARENTE; LOPES; MILÉO, 2020; OLIVEIRA; PARENTE; DOMINGUES, 2017).

Apesar de estarmos falando de uma metodologia de ensino, ela não se concretiza da mesma forma em todos os lugares e tempos. No curso Etnodesenvolvimento, a metodologia está entremeada nas maneiras de fazer educação e produzir conhecimento, na medida que do processo de formação ocorre em tempos e espaços diferenciados que dialogam entre si; experiência que forma ao mesmo tempo estudante e professores. O curso divide-se em dois tempos (TU e TC) e as disciplinas acompanham essa temporalidade na medida em que a maior parte da carga horária $(\mathrm{CH})$ é realizada no TU e outra no TC. $\mathrm{O} \mathrm{TU}$ ocorre nos períodos de janeiro/fevereiro e julho/agosto, acompanhando o calendário acadêmico da UFPA; ao final, os discentes levam atividades para serem realizadas em seus locais de origem, sendo acompanhados por docentes do curso, que monitoram as ações durante determinado período de tempo. Essa etapa findará com a entrega de documento escrito, em geral relatórios.

Com isso, o tempo em que os discentes ficam na universidade, às vezes, é menor em relação aos demais discentes do período intensivo, porque ainda existe a etapa do TC a ser cumprida, o que nem sempre é observado pelas pessoas que fazem comentários que "os estudantes do Etno não permanecem na universidade o tempo devido" ou "que tudo é mais facilitado para eles". Quem faz esses comentários ou pensa dessa maneira desconhece que o desenvolvimento das atividades na alternância pedagógica não adota o mesmo calendário acadêmico dos demais cursos, o que significa que o semestre para eles não finda com o término do período letivo, estendendo-se pelo período seguinte para finalizar as atividades semestrais ${ }^{5}$.

5 A UFPA trabalha com dois semestres: o primeiro se estende de janeiro a junho, e o segundo, de agosto a dezembro. Como a universidade é multicampi e tem cursos funcionando em período intensivo e extensivo, divide-se em quatro períodos: $1^{\circ}$ ) janeiro e fevereiro; $2^{\circ}$ ) fevereiro a junho; $3^{\circ}$ ) julho a agosto; $4^{\circ}$ ) julho a dezembro; sendo o $1^{\circ}$ e o $3^{\circ}$ intensivos; $2^{\circ}$ e $4^{\circ}$ extensivos. 
O monitoramento do TC nas comunidades representa a oportunidade de dialogar com os demais membros das comunidades, isso em reuniões noturnas e em outros momentos de convivência sociocultural. Constitui-se momento de trocas de informações entre a universidade e as comunidades, mas acima de tudo, o diálogo sobre suas experiências anteriores com a universidade, em que se sentiam apenas depositários dos estagiários da instituição que os enviava para suas comunidades e negavam os conhecimentos tradicionais dessas pessoas.

A partir da adoção da pedagogia da alternância, hoje percebemos uma aproximação substantiva entre a universidade e as comunidades, ao reconhecerem-se como parceiras nos processos formativos dos estudantes da universidade, acolhendo os professores nos momentos de orientação do TC dos parentes e/ou amigos que agora são reconhecidos como "alunos da universidade", pois como nos lembram Parente, Lopes e Miléo (2020), a pedagogia da alternância possibilita

[...] a organização didático-pedagógica horizontalizada que valoriza o experiencial vivido da diversidade de coletivos populares, traduzido no interior de uma rede de representações e significações em relação com a construção do saber (PARENTE; LOPES; MILÉO, 2020, p. 67).

A expectativa que as pessoas (a partir das comunidades visitadas no monitoramento do TC) nutrem com relação à sua participação na universidade faz com que os envolvidos (diga-se, nós da universidade) repensem o papel da universidade na sociedade, o que demonstra, minimamente, que a instituição precisa continuar trilhando o caminho da inclusão pelas políticas que diferenciam o acesso à universidade, aperfeiçoando cada vez mais as ferramentas para a permanência dos estudantes nela; as experiências nesse sentido têm sido extremamente exitosas, conforme o exemplo exposto e outros tantos podem comprovar, muito embora o sistema careça de melhoria para atender à especificidade do(s) curso(s) e dos discentes (PARENTE, 2014). 


\section{Pontuando algumas considerações...}

O Etnodesenvolvimento, como curso, é a possibilidade encontrada por profissionais de diferentes áreas de conhecimentos e povos e comunidades tradicionais para responder a uma demanda histórica e ainda urgente por ensino superior e diferenciado, em acordo às necessidades desses sujeitos e seus coletivos de pertença por autonomia para o exercício do direito de serem livres, com saúde, com educação e gestão territorial voltados para o fortalecimento e a valorização de suas formas de organização e representação política para o fortalecimento das suas comunidades, bem no sentido do termo/conceito cunhado nos anos 1980 (LUCIANO, 2006).

Num primeiro momento, a ideia era ampliar a formação dos sujeitos diferenciados que acessassem o curso de graduação em licenciatura e bacharelado em Etnodesenvolvimento, pensado a partir da premissa da diversidade cultural, centrado nas discussões da antropologia, arqueologia, direitos humanos, saúde e meio ambiente, para orientar seus planos e suas ações para a gestão de seus territórios e suas vidas. A dupla formação também favorecia a construção de ferramentas de atuação em diferentes espaços sociais, alargando as possibilidades de atuação no interior dos territórios de pertença ou fora deles, diretamente nas instituições governamentais, como escola ou posto de saúde, ou nas organizações locais, no diálogo com ou a partir do Estado.

Entretanto, fazer educação diferenciada traz consigo também o desafio de se repensar frente as políticas universalizantes do Estado, como a obrigatoriedade de separação das formações de licenciatura e bacharelado, que nos alcançou mais efetivamente a partir de 2015, com a necessidade de reestruturação do Projeto Pedagógico do Curso (PPC). Reestruturação que permitiu também repensar a proposta diferenciada de educação por meio do diálogo com os alunos em formação no curso, com os egressos para analisar suas trajetórias de atuação após a formação na graduação, seus coletivos e as demandas por ensino superior, e com os profissionais das universidades, parceiros na implantação e manutenção do curso.

Em todas as consultas feitas nesse sentido, a avaliação foi a de que a licenciatura conferiria uma resposta mais ampliada e efetiva às demandas das comunidades, que carecem de profissionais para construir e executar a educação diferenciada, voltada para a autonomia dos povos e comunidades tradicionais em seus territórios, além de contribuir para o planejamento e a gestão dos mesmos. 
Mas, acima de tudo, destacamos que estar na escola, ou mais precisamente na condição de professor ou gestor das instituições oficiais do Estado na comunidade, como a escola, permite repensar a política educacional e as práticas educativas por dentro, fazendo um trabalho de desconstrução da perspectiva colonial, positivação das identidades étnicas e diferenciadas e implementação de outros olhares, saberes e fazeres que venham ao encontro da escola/educação escolar para a autonomia das comunidades, valorizando os saberes locais e o diálogo entre os sujeitos em relação, independente do lugar de cada um, para a produção de outros conhecimentos, podendo ser a escola e seus atores os mediadores desse processo, inclusive e especialmente com o Estado.

Nesse sentido, a formação escolar alicerçada na alternância pedagógica tem sido percebida com uma das vias importantes para a consonância deste projeto diferenciado de formação educacional dialógica e coletiva, de construção de outras experiências de escolarização de sujeitos de direito, que permite as trocas de saberes e sua valorização na universidade e nas comunidades e contribui para a movimentação da engrenagem sociocultural local e extra local na medida em que verificam a viabilidade de formação voltada para afirmação das culturas e identidades étnicas e diferenciadas, verdadeiramente inclusivas, a partir de suas próprias experiências de ensino no curso e na universidade.

Esse é o momento atual da formação em Etnodesenvolvimento na UFPA. A partir de 2019, a Universidade passou a ofertar o curso de graduação em licenciatura que foi aprovado pela Resolução $\mathrm{N}^{0} 5.124$, de 23 de janeiro de 2019 - CONSEPE/UFPA (UNIVERSIDADE FEDERAL DO PARÁ, 2019), com os mesmos pressupostos epistemológicos, a partir da alternância pedagógica, com o objetivo de formar educadores habilitados como "Agentes de etnodesenvolvimento e/ou Etnoeducadores/as, que atendam às necessidades dos povos e comunidades tradicionais da Amazônia, com possibilidades de intervir socialmente" (UNIVERSIDADE FEDERAL DO PARÁ, 2019, p. 10), a partir de ações educativas que estabeleçam o diálogo entre conhecimento tradicional e conhecimento científico.

Independente da formação, os desafios para a educação diferenciada que se movimenta frente a uma contracorrente universalizante de escolarização permanecem, e é no diálogo com os povos e comunidades tradicionais, seus coletivos e a junção de profissionais de diferentes áreas de conhecimento que temos buscado responder às demandas mais urgentes das comunidades para 0 combate às desigualdades educacionais, e esses sujeitos têm assumido as suas escolas, postos de saúde e organizações coletivas fazendo a diferença nesses locais circunscritos em seus territórios de pertenças. 


\section{REFERÊNCIAS}

ARROYO, Miguel González. Outros sujeitos, outras pedagogias. Petrópolis, RJ: Vozes, 2012.

BARTOLOMÉ, Miguel Alberto. As etnogêneses: velhos atores e novos papéis no cenário cultural e político. Mana, Rio de Janeiro, v. 12, n. 1, p. 39-68, 2006. Disponível em: http:// www.scielo.br/scielo.php?script=sci_arttext\&pid=S0104. Acesso em: 26 maio 2020.

BONETI, Lindomar Wessler. Políticas públicas por dentro. Ijuí: Unijuí, 2006.

BONFIL BATALLA, Guillermo. México profundo. Una civilización negada. México: Debolsillo, 2006.

BRASIL. Presidência da República. Decreto $n^{\circ}$ 6.096, de 24 de abril de 2007. Institui o Programa de Apoio a Planos de Reestruturação e Expansão das Universidades Federais REUNI. Brasília, DF: Presidência da República, 2007. Disponível em: http://www.planalto. gov.br/ccivil_03/_Ato2007-2010/2007/Decreto/D6096.htm. Acesso em: 15 abr. 2021.

BRASIL. Conselho Nacional de Educação. Resolução $C N E / C P$ n. 02/2015, de $1^{\circ}$ de julho de 2015. Define as Diretrizes Curriculares Nacionais para a formação inicial em nível superior (cursos de licenciatura, cursos de formação pedagógica para graduados e cursos de segunda licenciatura) e para a formação continuada. Diário Oficial da União: Brasília, DF, seção 1, n. 124, p. 8-12, 02 jul. 2015.

CANDAU, Vera Maria. Direitos humanos, educação e interculturalidade: as tensões entre igualdade e diferença. Revista Brasileira de Educação, Rio de Janeiro, v. 13, n. 37 , p. 45-56, jan./abr. 2008. Disponível em: https://www.scielo.br/pdf/rbedu/v13n37/05. pdf. Acesso em: 17 jul. 2020.

CANDAU, Vera Maria. Diferenças culturais, cotidiano escolar e práticas pedagógicas. Currículo sem Fronteiras, [S. l.], v. 11, n. 2, p. 240-255, 2011. Disponível em: https:// www.curriculosemfronteiras.org/vol11 iss2articles/candau.htm. Acesso em: 16 abr. 2021.

GEERTZ, Clifford. A Interpretação das Culturas. Rio de Janeiro: LTC, 1989.

HALL, Stuart. A identidade cultural na pós-modernidade. Rio de Janeiro: DP\&A, 2000.

LITTLE, Paul Elliot. Etnodesenvolvimento local: autonomia cultural na era do neoliberalismo global. Tellus, Campo Grande, v. 2, n. 3, p. 33-52, 2002. Disponível em: https:/www.tellus.ucdb.br/tellus/article/view/23/32. Acesso em: 29 out. 2021.

LUCIANO, Gersem dos Santos. O Índio Brasileiro: o que você precisa saber sobre os povos indígenas no Brasil de hoje. Brasília, DF: MEC: SECAD: LACED/Museu Nacional, 2006. (Coleção Educação Para Todos). Disponível em: http://www.laced.mn.ufrj.br/ trilhas/. Acesso em: 15 maio 2020. 
MOEHLECKE, Sabrina. Ação Afirmativa: história e debates no Brasil. Cadernos de Pesquisa, São Paulo, n. 117, p. 197-217, nov. 2002. Disponível em: https://doi. org/10.1590/S0100-15742002000300011. Acesso em: 13 abr. 2021.

OLIVEIRA, Assis da Costa; PARENTE, Francilene de Aguiar; DOMINGUES, William César Lopes. Pedagogia da alternância e $(\mathrm{m})$ etnodesenvolvimento: realidade e desafios. Revista Educação \& Realidade, Porto Alegre, v. 42, n. 4, p. 1545-1565, out./dez. 2017. Disponível em: https://www.scielo.br/j/edreal/a/Yjg97qmsKXTR5KR3wrRGK8j/ abstract/?lang=pt. Acesso em: 13 abr. 2021.

PARENTE, Francilene de Aguiar. Educação Superior em Etnodesenvolvimento, Movimentos Indígenas e Agência da Diferença Étnica em Altamira/PA. Revista Fórum Identidades, Itabaiana, ano 8, v. 16, p. 221-246, jul./dez. 2014. Disponível em: https:// seer.ufs.br/index.php/forumidentidades/issue/view/387. Acesso em: 15 abr. 2021.

PARENTE, Francilene de Aguiar; LOPES, Raquel da Silva; MILÉO, Irlanda do Socorro de Oliveira. Pedagogia da Alternância na Formação de Professores Extrativistas: uma Experiência na Terra do Meio, em Altamira/PA. Revista Humanidades e Inovação, Tocantins, v. 7, n. 12, p. 63-77, 2020. Disponível em: https://revista.unitins.br/index. php/humanidadeseinovacao/issue/view/77. Acesso em: 15 abr. 2021.

PIOVESAN, Flávia. Ações Afirmativas e Direitos Humanos. Revista USP, São Paulo, n. 69, p. 36-43, mar./maio 2006. Disponível em: https://www.revistas.usp.br/revusp/ article/view/13511. Acesso em: 13 abr. 2021.

SANTOS, Boaventura de Sousa. Introdução: para Ampliar o Cânone do Reconhecimento, da Diferença e da Igualdade. In: SANTOS, Boaventura de Sousa (org.). Reconhecer para Libertar: os Caminhos do Cosmopolitanismo Multicultural. Rio de Janeiro: Civilização Brasileira, 2003. p. 25-68.

SANTOS, Boaventura de Sousa. A gramática do tempo: para uma nova cultura política. 2. ed. São Paulo: Cortez, 2008.

SANTOS, Glademir Sales dos. Etnografia da Inclusão. In: ALMEIDA, Allfredo Wagner Berno; SANTOS, Glademir Sales dos (org.). Estigmatização do Território: mapeamento situacional das comunidades e associações indígenas na cidade de Manaus. Manaus: Projeto Nova Cartografia Social da Amazônia/Editora da Universidade Federal do Amazonas, 2008. p. 63-81.

SOUZA LIMA, Antonio Carlos de; BARROSO-HOFFMANN, Maria; PERES, Sidnei Clemente. Notas sobre os Antecedentes Históricos das Idéias de "Etnodesenvolvimento" e de "Acesso de Indígenas ao Ensino Superior" no Brasil. Rio de Janeiro: LACED: Museu Nacional: UFRJ, 2002. p. 1-12. Disponível em: http://laced4.hospedagemdesites. ws/arquivos/Texto_Etnodesenvolvimento_e_Ensino_Superior_Indigenas.pdf. Acesso em: 25 ago. 2019.

STAVENHAGEN, Rodolfo. Etnodesenvolvimento: uma dimensão ignorada no pensamento desenvolvimentista. In: Anuário Antropológico. Brasília: UNB, 1984. p. $11-44$. 
UNIVERSIDADE FEDERAL DO PARÁ. Pró-Reitoria de Planejamento e Desenvolvimento Institucional. Plano de desenvolvimento da Universidade Federal do Pará: 2001-2010. Belém: EDUFPA, 2002.

UNIVERSIDADE FEDERAL DO PARÁ. Projeto Pedagógico do Curso de Etnodesenvolvimento. Altamira: EDUFPA, 2010

UNIVERSIDADE FEDERAL DO PARÁ. Pró-Reitoria de Planejamento e Desenvolvimento Institucional. Plano de desenvolvimento da Universidade Federal do Pará: 2011-2015. Belém: EDUFPA, 2011.

UNIVERSIDADE FEDERAL DO PARÁ. Conselho Superior de Ensino, Pesquisa e Extensão. Resolução n. 5.124, de 23 de janeiro de 2019. Aprova o Projeto Pedagógico do Curso de Licenciatura em Etnodesenvolvimento, de interesse do Campus Universitário de Altamira. Belém: UFPA, 2019. Disponível em: https://sege.ufpa. $\mathrm{br} /$ boletim_interno/downloads/resolucoes/consepe/2019/5124\%20Aprova $\% 20$ Projeto\%20Pedag\%C3\%B3gico\%20do\%20Curso\%20de\%20Licenciatura $\% 20 \mathrm{em} \% 20$ Etnodesenvolvimento\%20\%20Altamira.pdf. Acesso em: 9 out. 2021.

VERDUM, Ricardo. Etnodesenvolvimento: Nova/Velha Utopia do Indigenismo. Brasília, DF: Centro de Pesquisa e Pós-Graduação sobre as Américas/UnB, 2006. Disponível em: http://repositorio.bce.unb.br/bitstream/10482/2154/1/2006_Ricardo\%20Verdum. pdf. Acesso em: 25 ago. 2019.

Texto recebido em $04 / 12 / 2020$.

Texto aprovado em 15/06/2021. 